\title{
Effectiveness of counseling for anxiety and depression in mothers of children ages 0-30 months by community workers in Karachi, Pakistan: a quasi experimental study
}

\author{
Niloufer S Ali', Badar S Ali², lqbal S Azam*3 and Ali K Khuwaja4
}

\begin{abstract}
Background: The prevalence of anxiety/depression is quite high during the perinatal period but unfortunately its detection and treatment have been less than satisfactory. Moreover, many women are reluctant to take pharmacotherapy for fear of excretion of drugs into their breast milk. This study assesses the effectiveness of counseling from minimally trained community health workers in reducing anxiety/depression, the rate of recurrence and the interval preceding recurrence in women during first two and a half years after childbirth.

Methods: In a quasi-experimental study, community women from two under-privileged communities were trained in data gathering, teaching healthy child-rearing practices, basic counseling skills, and screening for anxiety/depression by using an indigenously developed questionnaire, the Aga Khan University Anxiety and Depression Scale (AKUADS). The diagnosis was further confirmed by a clinical psychologist using DSM IV criteria. After obtaining consent, 420 women were screened and 102 were identified as having anxiety/depression. Screening was carried out after 1, 2, 6, 12, 18,24 and 30 months of a live birth. Only 62 out of 102 agreed to be counseled and received eight weekly sessions. AKUADS was re-administered at 4 weeks and 8 weeks after the beginning of counseling; this was followed by the clinical psychologist's interview for confirmation of response. After recovery, screening was continued every 3 months for detection of recurrence throughout the study period. Out of the women who had declined counseling 12 agreed to retake AKUADS after 4 and 8 weeks of diagnosis. Independent samples t-test, chi-square test, Repeated Measures ANOVA and Kaplan Meier technique were used for the analysis.
\end{abstract}

Results: A significant decline in level of anxiety/depression was found in both the counseled and the non-counseled groups at 4 and 8 weeks ( $p$-value $<0.001$ ) but the counseled group fared better than the non-counseled for recovery, reduction in the rate of recurrence and increase in the duration before relapse.

Conclusions: As our results cannot be generalized; further studies need to be carried out, to assess the benefit of incorporating minimal counseling skills in the training of community health workers.

\section{Background}

Globally the prevalence of mental health and psychosocial problems is high during pregnancy and after birth. It is reported that almost one in four women in developing countries suffers from anxiety/depression around the period of childbirth [1], which can lead to a chronic or recurring depressive course throughout life [2]. A litera-

* Correspondence: iqbal.azam@aku.edu

3 Department of Community Health Sciences, Aga Khan University, Karachi, Pakistan, Stadium Road, P. O. Box 3500, Karachi 74800, Pakistan Full list of author information is available at the end of the article ture review of 143 research studies undertaken in 40 countries around the world reported that the prevalence of postpartum depression (PPD) in Asian countries ranged from $11 \%$ to $60.8 \%$ [3].

The mean overall prevalence of anxiety and depressive disorders in the Pakistani population has been reported to be $34 \%$ with higher rates in women than in men [4]. Ali et al have reported a prevalence of $30 \%$ among women of reproductive age group in a semi-urban community of Karachi, Pakistan [5]. Studies done in urban tertiary care 
settings in Pakistan, have reported figures ranging from $24 \%-42 \%$ [6,7]. Other community-based studies from rural Pakistan have reported prevalence ranging from $28 \%-36 \%$ in postpartum women [8,9]. A cohort study from rural Pakistan has reported persistent postpartum depression in 56\% of those who developed PPD [10].

Depression after childbirth affects the health of the mother as well as the health, growth and development of the child [11]. Studies have revealed that perinatal depression is associated with poor growth, high risk of diarrhoea and reduced uptake of immunization $[12,13]$.

Currently the detection and treatment of depression after childbirth is less than satisfactory and many women are reluctant to take pharmacotherapy for fear of excretion of drugs into their breast milk [14]. Studies from high income countries have reported that psychotherapeutic approaches, such as cognitive behaviour therapy, interpersonal therapy or problem solving therapy are effective treatments for depression [15]. A few randomized trials from low income and middle income countries have also reported similar findings $[16,17]$. Substantial decrease in depressive symptoms in women after miscarriage has been reported after six sessions of interpersonal counseling [18]. A randomized controlled study conducted by Rahman et al in a poor rural community in Pakistan has shown that integration of cognitive behaviour therapy (CBT) into routine work of community health workers more than halved the rate of depression in prenatally depressed women compared with those receiving routine care only. In addition to symptomatic relief, the intervention group had less disability, better overall social functioning and the benefit persisted after one year [19]. Bhar et al have reported that patients treated with either pharmacotherapy or cognitive therapy showed similar results [20].

No published findings to date suggest that antidepressant medication reduces future risk of depressive episodes after discontinuation [21], whereas cognitive therapy has been shown to provide protection against relapse and possible recurrence [22]. Hollon et al have reported higher percentages of relapses and recurrences among patients who were on pharmacotherapy than on cognitive therapy [23].

In a randomized controlled trial Ali et al. found significant improvement in women of reproductive age who were suffering from anxiety and depression after eight weekly counseling sessions by minimally trained community women [24]. Based on this experience, this study was conducted to assess the benefits of counseling from minimally trained community health workers working with anxious and depressed women during the first two and a half years after childbirth, and to assess the rate of recurrence and the interval preceding recurrence of anxiety/ depression after counseling.

\section{Methods}

\section{Study design, site and duration}

This is a quasi-experimental study from an action research program to assess "The effect of postpartum anxiety and depression on early childhood growth and development," implemented in two semi-urban underprivileged communities (Qayoomabad and Manzoor Colony) of Karachi, a mega city of Pakistan from February 2004 to January 2007.

\section{Study participants and sample}

A total of 420 consenting women (155 from Manzoor Colony and 265 from Qayoomabad) were enrolled after live childbirths. Out of these, 102 women (34 from Manzoor Colony and 68 from Qayoomabad) developed anxiety/depression during the study period. Detailed information about the recruitment process is given elsewhere [25].

\section{Instruments used \\ a. Aga Khan University Anxiety and Depression Scale (AKUADS)}

This is a screening instrument for anxiety and depression developed from symptoms of anxious and depressed patients noted verbatim in the local lingua franca Urdu and validated in the community keeping the psychiatrist's interview as the gold standard [26,27]. It is a 25 item scale (13 psychological and 12 somatic items) that covers most of the clinical features considered characteristic of anxiety and depressive disorders. Each item has four response options (never, sometimes, often, always) scored from 0 to 3 . At a cut-off score of 19 it has a sensitivity of $74 \%$, specificity of $81 \%$, a positive predictive value of $63 \%$ and a negative predictive value of $88 \%$ [27]. It has been used in several studies in Pakistan due to its near 100\% linguistic validity [5,24-29]. As AKUADS is a screening instrument, diagnostic confirmation was obtained by a clinical psychologist's interview. Mothers who tested positive on AKUADS (score of 19 or above) and those who were marginally below the cut-off score i.e. with scores of 17 and 18 were interviewed by a clinical psychologist for confirmation of diagnosis according to DSM IV criteria. However, women with a score of 16 and below were considered as not anxious/depressed and were not interviewed by the clinical psychologist.

\section{b. Socio-demographic questionnaire}

This included mother's age, religion, ethnicity, education and occupation, husband's education and occupation, monthly household income (in Pakistani Rupees), ownership of house, total number of rooms, total number of household members, number of pregnancies, number of live births, number of abortions/stillbirths, number of deceased children, reasons for their deaths, whether the current pregnancy was planned or otherwise, if the sub- 
ject had ever used or had intended to use contraception and had the autonomy to do so.

\section{c. Home environment/Family relationship questionnaire}

included presence or absence of a stressful home environment, satisfaction with current life, available family/social support, how household decisions were made, if the mother or the children were ever abused physically or verbally by any family member.

\section{d. Post-natal questionnaire}

recorded the gender, date, weight (in kg.), place of birth, qualification of the birth attendant, complications, if any, during or after birth in the mother or the newborn.

\section{e. Early childhood development (ECD) tool}

which comprised five major components of development i.e. gross motor, fine motor, language, cognitive and socio-emotional development.

\section{Selection and training of field workers as counselors}

Women aged 18 years and above residing at the study sites, able to read and write Urdu (the lingua franca in Pakistan) and willing to be trained were identified. They were trained in administration of the screening instrument, The Aga Khan University Anxiety and Depression Scale (AKUADS), and the other study questionnaires mentioned above. They were also trained to provide counseling to mothers who were found to be anxious and depressed. The training extended over 5 half days per week, for four weeks, each session being of three hours. The trainers included two family practitioners, a psychiatrist and a clinical psychologist. The training encompassed basic information regarding anxiety/depression, stress/anger management and communication/counseling skills. Communication covered principles of active listening, probing and feedback, whereas counseling dealt with supportive, problem-solving and basic cognitivebehavioral techniques. The model used was participatory and facilitatory. Out of the 19 trained women, 11 were selected as counselors based on their ability to maintain confidentiality, communicate empathically and to gain permission from family to move freely in the community.

In addition, they were trained in monitoring the growth and development of the indexed baby by measuring weight, height and head circumference. They were also trained in using the early childhood development (ECD) tool and in providing information regarding healthy child-rearing practices which included: care of the cord, avoiding traditional harmful practices like application of surma (an eye cosmetic believed to heal eye infection and available as a fine powder of lead sulfide), promoting breast feeding, and advice on timely weaning and immunization.

\section{Enrolment and data collection}

A field office was established at Qayoomabad and the counselors visited each house in Qayoomabad and adja- cent sectors of Manzoor colony, and inquired about the date of the last menstrual period from women in the reproductive age group. Those found to be pregnant were informed of the objectives of the study and were invited to participate in the study after childbirth and written consent was obtained. This process of identification of pregnant women was carried on for the first two years of the study. The expected date of delivery was calculated from the date of the last menstrual period and the counselors started weekly home visits when the participant woman had reached the $36^{\text {th }}$ week of pregnancy, and this continued until childbirth. Consent was again obtained from mothers of live births before enrolling them in the study. The socio-demographic, home environment, family relationship and newborn postnatal questionnaires were administered within seven to ten days of childbirth by the counselors. Routine follow-ups were scheduled after 1, 2, 6, 12, 18, 24 and 30 months of childbirth for screening of anxiety/depression among mothers and monitoring of child growth/development. Verbal consent was obtained each time before administering AKUADS. Women with AKUADS scores of 17 or above were interviewed by the clinical psychologist for confirmation of anxiety/depression according to DSM IV criteria.

A total of 102 women were found to be anxious and depressed at least once during the study period. Among them 84 had only one episode, 16 had two episodes and 2 women suffered three episodes giving a total of 122 episodes. (Table 1).

The number of episodes of anxiety/depression at 1 month, 2 months, 6 months, 12 months, 18 months, 24 months and 30 months were 14, 14, 27, 35, 18, 12 and 2 respectively. All women found to be anxious/depressed by the clinical psychologist or who scored 19 or above on AKUADS were offered weekly one-hour counseling sessions for eight weeks. Only 62 accepted; main reasons for refusal were objection from their husbands and in-laws and the social stigma attached to the diagnosis of a mental illness. Very basic cognitive behavioral therapy, supportive and problem-solving counseling was provided. Sessions were conducted at the client's residence on the day and time of her convenience. The counselors kept notes of their sessions and discussed these with the clinical psychologist on a daily basis initially, and once weekly as they became better trained and more confident. They also had easy access to the other members of the training team throughout the study period. All identified women whether they had agreed to counseling or not were requested to take the AKUADS at 4 and 8 weeks after being diagnosed. Those women whose AKUADS scores after 8 weeks of counseling were 16 and below were considered to have recovered and those with a score of 17 or above were interviewed by the clinical psychologist for the confirmation of persistence of anxiety/depression. Only five of them ( $\mathrm{n}=3$ counseled; $\mathrm{n}=2$ non-counseled) 
Table 1: Distribution of episodes of anxious and depressed women with their AKUADS scores at the time of identification by month of identification and area of residence $(n=122)$

\begin{tabular}{|c|c|c|c|c|c|c|c|c|}
\hline \multirow[t]{2}{*}{ AKUADS scores at the time of identification* } & \multicolumn{7}{|c|}{ Month of Identification } & \multirow[t]{2}{*}{ All } \\
\hline & 1 & 2 & 6 & 12 & 18 & 24 & 30 & \\
\hline \multicolumn{9}{|c|}{ Manzoor Colony (MC) } \\
\hline Number of women Interviewed & 155 & 147 & 112 & 94 & 76 & 56 & 17 & 155 \\
\hline $19+$ & 3 & 5 & 11 & 9 & 4 & 3 & 0 & 35 \\
\hline$>16 \&<19$ & 0 & 0 & 0 & 1 & 1 & 1 & 1 & 4 \\
\hline MC & 3 & 5 & 11 & 10 & 5 & 4 & 1 & 39 \\
\hline \multicolumn{9}{|c|}{ Qayoomabad (QA) } \\
\hline Number of women Interviewed & 265 & 255 & 223 & 173 & 150 & 109 & 59 & 265 \\
\hline $19+$ & 10 & 9 & 13 & 25 & 12 & 7 & 0 & 76 \\
\hline$>16 \&<19$ & 1 & 0 & 3 & 0 & 1 & 1 & 1 & 7 \\
\hline QA & 11 & 9 & 16 & 25 & 13 & 8 & 1 & 83 \\
\hline All & 14 & 14 & 27 & 35 & 18 & 12 & 2 & 122 \\
\hline
\end{tabular}

did not recover after eight weeks of identification and were advised to seek pharmacological treatment. Those who had recovered from anxiety and depression were then followed regularly according to the study protocol for recurrence during the study period. Recurrence was considered when, at any follow-up visit the AKUADS score was found to be 17 and above, and confirmation was also obtained from the psychologist. Two suicidal patients were referred for treatment and were not included in the study. The flow of participants is shown in Figure 1.

All women enrolled in the program, irrespective of whether they were anxious/depressed or not or whether they were being counseled or not, were instructed in healthy child rearing practices and the growth and development of their indexed child was monitored.

\section{Data management and analysis}

Data was double entered using EpiData (version 3.02) package; $10 \%$ of the records were randomly checked to assess the quality of data entry. The final data were analyzed using the statistical software package SPSS (Statistical Package for Social Sciences; version 15.0).
Independent samples t-test for the mean differences by counseling status (counseled and not counseled that had accepted to take AKUADS) were observed for quantitative variables like age, gravidity, baseline AKUADS scores, total number of rooms in the house, and total number of persons per household.

A chi-square test was used to observe the association between different socio-demographic categorical variables by counseling status. The categorical variables studied were the couple's education, mother tongue, history of domestic violence, religion, migrant status, ownership of house, past history of still births, gender of the newborn, qualification of the birth attendant, place of delivery and difficulty in breast feeding. Among the noncounseled group, same statistical techniques were used to assess the association of these variables with the groups who had refused counseling but had accepted taking AKUADS at 4 and 8 weeks and those who had refused to do so.

Repeated Measures ANOVA was used to see the difference in the AKUADS scores and an error chart was made with $95 \%$ confidence interval for mean AKUADS score at 


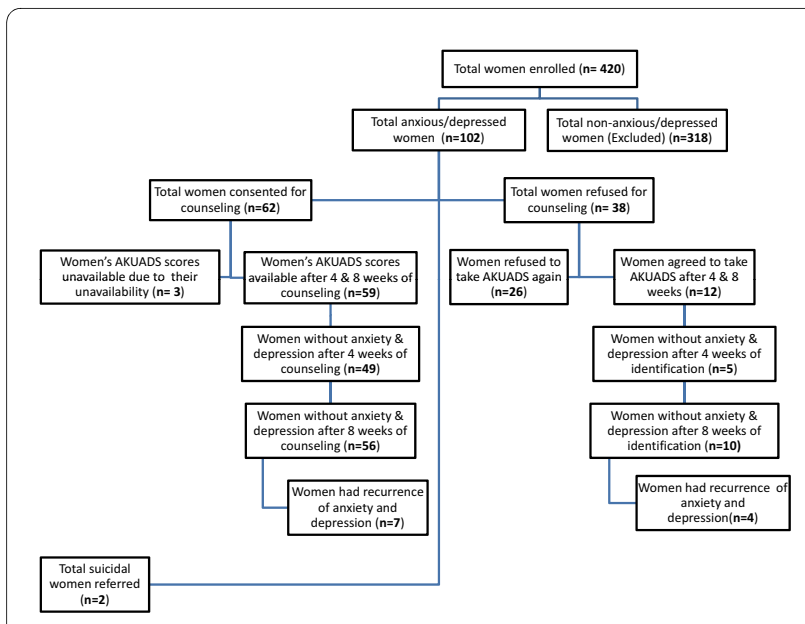

Figure 1 Flow Chart of women identified as anxious and depressed.

the time of initial diagnosis, and after 4 weeks and 8 weeks of diagnosis by counseling status. Pairwise comparisons were made using Bonferroni's method. Partial Eta square was used to report effect sizes for each component. The Kaplan Meier method was used to calculate the mean recurrence time with $95 \%$ confidence intervals for the counseled and the not counseled and log rank test was used to assess the significant difference in the mean recurrence time. A p-value of 0.05 was considered as significant.

\section{Results}

Out of the 420 women enrolled, 102 women were found to be anxious and or depressed with a total of 122 episodes, based on the AKUADS score and supplemented by the clinical psychologist's interview. AKUADS scores after 4 and 8 weeks were only available for seventy one women i.e. 59 from the counseled and 12 from the not counseled group (Figure 1).

The association of different characteristics by counseling status was observed. No significant differences were found for variables such as age, level of education, past history of anxiety and depression, husband's education, religion, mother tongue, migrant status, ownership of house, total number of rooms, total number of persons per household, gravidity, past history of still birth, satisfaction with current life, domestic violence, gender of the newborn, qualification of the birth attendant and place of birth. The characteristics having a significant association were difficulty in breast feeding $\left(\mathrm{x}^{2}(2)=11.824\right.$, $\mathrm{p}$-value $=$ 0.002 ) and study area (Fisher Exact(1), p-value $=0.049$ ). The average AKUADS score at the time of diagnosis was significantly higher in those who had refused counseling as compared to those who had agreed to and received counseling $(\mathrm{Z}=-3.764$, p-value $<0.001)$ (Table 2).
Repeated measures ANOVA of AKUADS scores of anxious/depressed women after the $4^{\text {th }}$ and $8^{\text {th }}$ weeks of identification showed significant effects of time (Time: $\mathrm{F}(2,142)=37.89, \mathrm{p}$-value $<0.001 ;$ Partial Eta square $=$ $0.348)$, interaction between time \& counseling status (TimexCounseling Status: $\mathrm{F}(2,142)=3.577$, $\mathrm{p}$-value $=$ 0.031; Partial Eta square $=0.048)$ and counseling status (Counseling Status: $\mathrm{F}(1,71)=14.071$, p-value $<0.001$; Partial Eta square $=0.165)($ Figure 2).

Pair-wise comparisons of mean AKUADS scores using Bonferroni's method were made for all time points (when identified, after $4^{\text {th }}$ and $8^{\text {th }}$ weeks of identification) and were found significant ( $p$-value $<0.001$ ) for all time points pairs. Similarly, pair-wise comparisons for counseling status at each time point were made and mean AKUADS scores at the time of identification (p-value < 0.001 ) and after $4^{\text {th }}$ week of identification ( $\mathrm{p}$-value $<$ 0.001 ) were found to be significant.

During the overall study period from February 1, 2004 to January 31,2007 , post-test data were available for 71 women diagnosed as anxious and depressed at induction in the study ( $\mathrm{n}=59$ counseled; $\mathrm{n}=12$ non-counseled). Out of them 54 women had recovered after 4 weeks $(\mathrm{n}=$ 49 counseled; $\mathrm{n}=5$ non-counseled) and 66 women after 8 weeks. ( $\mathrm{n}=56$ counseled; $\mathrm{n}=10$ non-counseled) (Figure 1).

During the regular follow-up, recurrence of anxiety and depression was observed in 7 women among the counseled group and in 4 women among the non-counseled group. The earliest recurrence time in the counseled group was 9 months and the latest was 26 months as compared to the not counseled in which the earliest recurrence occurred at 3 months and the latest at 12 months. No significant difference was observed in the mean recurrence time between the counseled (Mean = 22.8 months, $\mathrm{SE}=1.2$ months; 95\% C.I.: 20.4, 25.3) and not counseled group (Mean $=17.7$ months, $\mathrm{SE}=2.9 ; 95 \%$ C.I.: 12.0, 23.4) $\left(\log \operatorname{Rank} \chi^{2}(1)=2.33\right.$, p-value $\left.=0.127\right)$, (Figure 3).

\section{Discussion and Conclusions}

The findings of this study suggest that after 4 and 8 weeks the scores of AKUADS, (both the counseled and not counseled groups) showed a significant decline from the initial scores, but the counseled group fared better than the not counseled. Rahman et al have reported that integration of a cognitive-behavior-therapy-based intervention by community health workers had substantially reduced the rate of depression in prenatally depressed women compared with those receiving routine care [19]. DeRubeis et al have also reported that cognitive therapy can be as effective as medications in the initial treatment of moderate to severe major depression [30]. 
Table 2: Comparison of different characteristics of study participants by counseling status

\begin{tabular}{|c|c|c|c|c|}
\hline Characteristics & $\begin{array}{c}A I I \\
(n=71)\end{array}$ & $\begin{array}{c}\text { Counseled } \\
(n=59)\end{array}$ & $\begin{array}{c}\text { Not-counseled } \\
(n=12)\end{array}$ & Pvalue \\
\hline Study Area & & & & 0.049 \\
\hline Qayoomabad & 47 & 36 & 11 & \\
\hline Manzoor Colony & 24 & 23 & 1 & \\
\hline Age Group & & & & 0.077 \\
\hline$<25$ & 20 & 17 & 3 & \\
\hline $25-29$ & 27 & 24 & 3 & \\
\hline $30-34$ & 17 & 14 & 3 & \\
\hline $35 \&$ above & 7 & 4 & 3 & \\
\hline Mean age (SD) & $27.4(5.0)$ & $26.9(4.7)$ & $29.8(5.9)$ & \\
\hline Educational Level & & & & 0.075 \\
\hline Illiterate & 18 & 15 & 3 & \\
\hline Can read \& write & 6 & 3 & 3 & \\
\hline Below matriculation & 24 & 23 & 1 & \\
\hline Matriculation & 12 & 10 & 2 & \\
\hline Intermediate \& above & 11 & 8 & 3 & \\
\hline Past History of Anxiety or Depression & & & & 0.207 \\
\hline Yes & 9 & 9 & 0 & \\
\hline No & 62 & 50 & 12 & \\
\hline Difficulty in breast feeding & & & & 0.002 \\
\hline No & 57 & 51 & 6 & \\
\hline \multicolumn{5}{|l|}{ Yes } \\
\hline Mother & 9 & 7 & 2 & \\
\hline Baby & 5 & 1 & 4 & \\
\hline $\begin{array}{l}\text { AKUADS Scores when diagnosed as } \\
\text { anxious and depressed* }\end{array}$ & & & & $<0.001$ \\
\hline Mean (SD; Min. Score, Max. Score) & $20.5(6.4 ; 7,57)$ & $19.3(3.6 ; 7,27)$ & $26.1(11.9 ; 12,57)$ & \\
\hline
\end{tabular}

* Based on the number of episodes all $=73$, counseled $=60$ and not counseled $=13$

Lack of autonomy is one of the known vulnerability factors for anxiety/depression and our results support this finding as the AKUADS scores at the time of identification were higher among the group that could not be counseled because of lack of permission from the family.

The significant decline in the not counseled group suggests several possibilities such as the fact that lapse of time since delivery itself tends to reduce anxiety/depres- sion in women, or that it reflects the natural history of anxiety/depression that waxes and wanes. It could also be the result of enhanced social support because of regular visits from counselors, monitoring of growth and development of the indexed child and learning healthy childrearing practices by all mothers. The later possibility also makes it difficult to ascertain the decline in scores of the counseled group as resulting from purely counseling to 


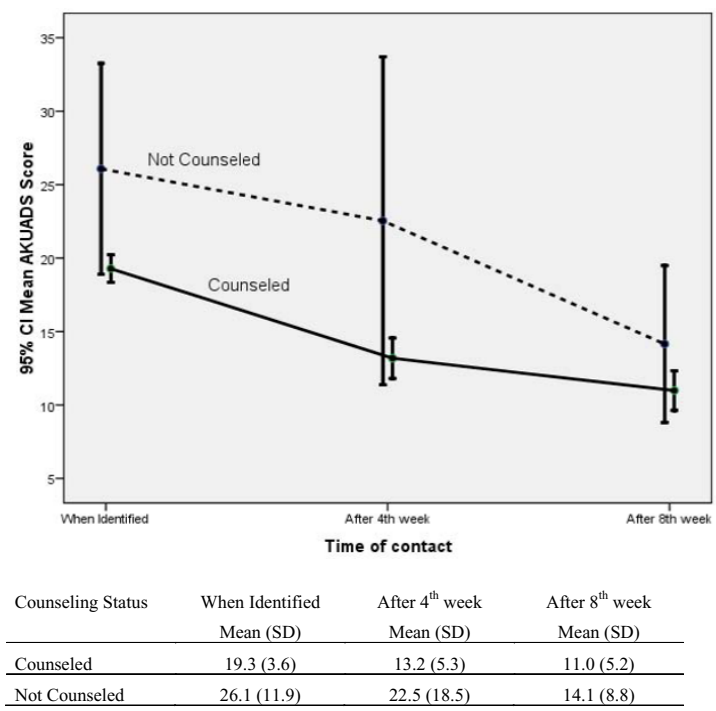

Figure 2 Mean AKUADS Score (95\% confidence interval) by Time of Contact in counseled and not counseled women. $(n=71)$.

the actual or perceived social support experienced by the group.

A meta-analysis published in The Cochrane Database of Systemic Reviews 2007 suggests that psychosocial and psychological interventions are both effective treatment options for postpartum depression [31]; our results also suggest that probably psycho-social support alone and in combination with counseling could benefit postpartum women with anxiety and depression, the separate contribution of each one cannot be determined as the data is from an action research program and not a randomized controlled trial.

More recently, a randomized controlled study has suggested that interpersonal psychotherapy ameliorates

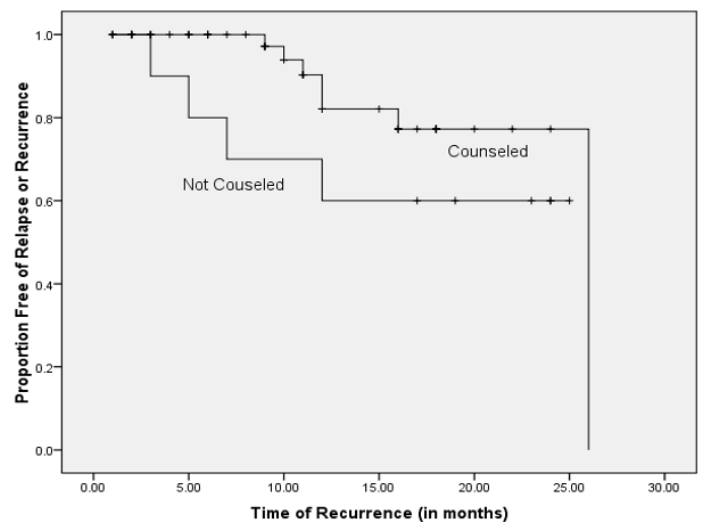

Figure 3 Kaplan Meier Survival Curves estimating time until recurrence by Counseling Status ( $n=11$ ). depression during pregnancy and prevents depressive relapse and improves social functioning up to six months postpartum [32]. Varying recurrence rates have been reported $[33,34]$ for various types of psychotherapy, from 26\%-67\%. It has been reported that cognitive behavior treatment (CBT) resulted in a significantly lower relapse rate $(40 \%)$ at a 6 year follow up [35] than pharmacological management (90\%). In our study, which was conducted over a period of 30 months, we found an overall recurrence rate of $16.4 \%$, with a marginally significant difference $(p$-value $=0.051)$ between the counseled $(12.3 \%)$ and the non counseled groups (28.6\%). The recurrence rate in the counseled group is lower than that mentioned in the studies referred above, as probably our study population had mild to moderate depression due to the fact that suicidal patients and those who had not responded to eight sessions of counseling were referred for treatment; for ethical reasons these patients had continued to be counseled but were not included in the analysis.

In our study we also observed that minimum time interval before recurrence was longer in the counseled i.e. 9 months as compared to the not counseled in which it was 3 months. Cognitive therapy has demonstrated an enduring effect that prevents the return of symptoms after successful treatment [36]. Dobson et al have also reported that cognitive therapy has an enduring effect and is a less expensive and longer-lasting alternative to medications [37]. Ali et al have consistently found an encouraging response to counseling by minimally trained community women in underprivileged communities $[24,38]$.

One of the limitations of our study was that the Ethics Committee of the Aga Khan University declined to approve a randomized controlled trial, as one of our investigators had earlier established the benefit from counseling by minimally trained counselors in the same community [24]. Another limitation is that a majority of the non-counseled group refused to take the AKUADS after 4 and 8 weeks of initial identification, leaving us with small numbers for comparison. The third limitation is that those women who were enrolled towards the end of the study could not be followed for a longer period of time. This could also possibly be a reason for a lower recurrence rate (16.4 percent). The fourth limitation is that the interviewers were not blind to the counseling status of the women interviewed at $4^{\text {th }}$ and $8^{\text {th }}$ weeks followup as they themselves were the counsellors.

In addition, this study was conducted in two underprivileged urban communities; hence, the study participants may not completely represent the city population.

\section{Recommendations}

Depression after childbirth is of great concern to primary and mental health-care professionals. In most developing 
countries primary care practitioners neither have the time nor the skill to counsel patients; and certified psychologists/counselors are very few. They are mostly restricted to big cities and are inaccessible and unaffordable for most of the population. Moreover, these countries cannot afford the luxury of developing a special cadre of community health workers taking care of mental health problems only. Therefore, it is recommended that minimal skills for identification and counseling for anxiety/depression should be incorporated in the training of community health workers to improve the mental health of women with anxiety and depression in resourcestrained countries. Above all, there is widespread stigma and skepticism attached to conventional psychiatric services which act as barriers for use even when available. Hence community-based counseling services, besides being accessible and affordable, would probably be more acceptable.

\section{Authors information}

Dr. Niloufer S Ali: MBBS, DCH, MCPS, FCPS. Associate Professor, Department of Family Medicine, The Aga Khan University, Karachi, Pakistan.

Dr. Badar S Ali: MBBS, FCPS. Senior Clinical Lecturer, Department of Family Medicine, The Aga Khan University, Karachi, Pakistan.

Mr. Iqbal S Azam: BSc (Honors), MSc (Statistics). Assistant Professor and Coordinator Statistical Consulting Services, Department of Community Health Sciences, The Aga Khan University, Karachi, Pakistan.

Dr. Ali K Khuwaja: MBBS, MCPS, FCPS. Assistant Professor and Convener Research, Department of Family Medicine \& Community Health Sciences, The Aga Khan University, Karachi, Pakistan.

\section{Competing interests}

The authors declare that they have no competing interests.

\section{Authors' contributions}

NSA conceived and designed the study and prepared the manuscript. BSA designed the study questionnaire and provided intellectual feedback. ISA managed, analyzed, interpreted the data and provided feedback throughout. AKK provided constructive intellectual feedback and participated in the revision of manuscript. All authors read and approved the final manuscript.

\section{Acknowledgements}

We are indebted to The Aga Khan University Research Council, which provided a grant for conducting this study. We are also grateful to the administration of Sir Syed hospital for providing space for training community based workers and Ghaffoor Memorial Welfare Trust for providing us with a field office during the study period. We would like to acknowledge the efforts of our community based workers, field supervisor Ms Asia and clinical psychologist Ms Ghurnata Tabassum in conducting the study. We would also like to acknowledge Dr Graeme Cane, Head, Centre of English Language, Institute for Educational Development, The Aga Khan University for copyediting the manuscript as native English speaking colleague. Last but not least, we wish to acknowledge the cooperation of the people of Qayoomabad and Manzoor Colony without whose participation, this study would not have been possible.

Funding: The project was funded by The Aga Khan University Research Council (Grant number: 022006 CHS).
Ethics approval: Ethical approval was obtained from the Ethics Committee of the Aga Khan University.

\section{Author Details}

'Department of Family Medicine, Aga Khan University Stadium Road, P. O. Box 3500, Karachi 74800, Pakistan, ${ }^{2}$ Department of Family Medicine, Aga Khan University, Karachi, Pakistan, Stadium Road, P. O. Box 3500, Karachi 74800, Pakistan, ${ }^{3}$ Department of Community Health Sciences, Aga Khan University, Karachi, Pakistan, Stadium Road, P. O. Box 3500, Karachi 74800, Pakistan and 4Department of Family Medicine \& Community Health Sciences, Aga Khan University Stadium Road, P. O. Box 3500, Karachi 74800, Pakistan

Received: 29 May 2009 Accepted: 19 July 2010

Published: 19 July 2010

\section{References}

1. Patel V, Rodrigues M, Gender DeSouza N: Poverty and post- natal depression: a cohort study from Goa, India. Am J Psychiatry 2002, 159:43-7.

2. Goodman JH: Postpartum depression beyond the early postpartum period. J Obstet Gynecol Neonatal Nurs 2004, 33(4):410-420.

3. Halbreich U, Karkun S: Cross cultural and social diversity of prevalence of postpartum depression and depressive symptoms. J Affect Disord 2006, 91(2):97-111.

4. Mirza I, Jenkins R: Risk factors, prevalence, and treatment of anxiety and depressive disorders in Pakistan: systematic review. BMJ 2004, 328:794

5. Ali BS, Rahbar MH, Naeem S, Tareen Al, Gul A, Samad L: Prevalence of and factors associated with anxiety and depression among women in a lower middle class semi-urban community of Karachi, Pakistan. J Pak Med Assoc 2002, 52(11):513-517.

6. M.Quraishy A, Sultana K, Riaz Z: Postpartum Depression: Liaquat National Hospital Experience. Medical Channel 2005, 11(1):30-32

7. Hamirani MM, Sultana A, Ibrahim Z, Sultana S, Humera : Post natal depression at a tertiary care hospital in Karachi. Ann Abbasi Shaheed Hosp Karachi Med Dent Coll 2004, 9(1):517-520.

8. Rahman A, Iqbal Z, Harrington R: Life events, social support and depression in childbirth: perspectives from a rural community in the developing world. Psychological Medicine 2003, 33:1161-7.

9. Husain N, Bevc I, Husain M, Chaudhry IB, Atif N, Rahman A: Prevalence and social correlates of postnatal depression in a low income country. Arch Womens Ment Health 2006, 9:197-202.

10. Rahman A, Creed F: Outcome of prenatal depression and risk factors associated with persistence in the first postnatal year: Prospective study from Rawalpindi, Pakistan. J Affect Disord 2007, 100(1-3):115-121.

11. Leiferman J: The effect of maternal depressive symptomatology on maternal behaviours associated with child health. Health Education Behaviour 2002, 21(5):596-607.

12. Rahman A, lqbal Z, Bunn J, Lovel H, Harrington R: Impact of maternal depression on infant nutritional status and illness: a cohort study. Arch Gen Psychiatry 2004, 61:946-952.

13. Rahman A, Bunn J, Lovel H, Creed F: Maternal depression increases infant risk of diarrhoeal illnesses - a cohort study. Arch Dis Child 2007, 92:24-28.

14. Eberhard-Gran M, Eskild A, Opjordsmoen S: Use of psychotropic medications in treating mood disorders during lactation: practical recommendations. CNS Drugs 2006, 20(3):187-198.

15. Churchill R, Hunot V, Corney R, Knapp M, McGuire H, Tylee A, Wessely S: A systematic review of controlled trials of the effectiveness and cost effectiveness of brief psychological treatments for depression. Health Technol Assess 2001, 5:1-173.

16. Patel V, Araya R, Chatterjee S, Chisholm D, Cohen A, De Silva M, Hosman C, McGuire H, Rojas G, Van Ommeren M: Treatment and prevention of mental disorders in low income and middle income countries. Lancet 2007, 370:991-1005.

17. Rojas G, Fritsch R, Solis J, Jadresic E, Castillo C, Gonzalez M, Guajardo V, Lewis G, Peters TJ, Araya R: Treatment of postnatal depression in low income mothers in primary care clinics in Santiago, Chile: a randomized controlled trial. Lancet 2007, 370:1629-37.

18. Neugebauer R, Kline J, Bleiberg K, Baxi L, Markowitz JC, Rosing M, Levin B, Keith J: Preliminary open trial of interpersonal counseling for 
subsyndromal depression following miscarriage. Depress Anxiety 2007, 24(3):219-22.

19. Rahman A, Malik A, Sikander S, Roberts C, Creed F: Cognitive behaviour therapy-based intervention by community health workers for mothers with depression and their infants in rural Pakistan: a clusterrandomised controlled trial. Lancet 2008, 372:902-09.

20. Bhar SS, Gelfand LA, Schmid SP, Gallop R, DeRubies RJ, Hollon SD, Amsterdam JD, Shelton RC, Beck AT: Sequence of improvement in depressive symptoms across cognitive therapy and pharmacotherapy. J Affect Disord 2008, 110:161-166

21. American Psychiatric Association: Practice guideline for the treatment of patients with major depressive disorder. Am J Psychiatry 2000, 157(Suppl 4):1-45.

22. Hollon SD, Thase ME, Markowitz JC: Treatment and prevention of depression. Psychol Sci Public Interest 2002, 3:39-77.

23. Hollon SD, DeRubies RJ, Shelton RC, Amsterdam JD, Saloman RM, O'Reardon JP, Lovett ML, Young PR, Haman KL, Freeman BB, Gallop R: Prevention of relapse following cognitive therapy vs medications in moderate to severe depression. Arch Gen Psychiatry 2005, 62:417-422.

24. Ali BS, Rahbar MH, Naeem S, Gul A, Mubeen S, labal A: The effectiveness of counselling anxiety and depression by minimally trained counselors: a randomized controlled trail. Am J Psychother 2003, 57:324

25. Ali NS, Ali BS, Azam IS: Post partum anxiety and depression in peri urban communities of Karachi, Pakistan: a quasi-experimental study. BMC Public Health 2009, 9:384.

26. Ali BS, Reza H, Khan MM, Jehan I: Development of an indigenous screening instrument in Pakistan: The Aga Khan University Anxiety and Depression Scale. J Pak Med Assoc 1998, 48:261-65.

27. Ali BS: Validation of an indigenous screening questionnaire for anxiety and depression in an urban squatter settlement of Karachi. J Coll Physicians Surg Pak 1998, 8:207-11.

28. Rabbani F: Views about women's mental health: study in a squatter settlement of Karachi. J Pak Med Assoc 1999, 49:139-42.

29. Karmaliani R, Bann Cm, Pirani F, Akthar S, Bender RH, Goldenberg RL, Moss $\mathrm{N}$ : Diagnostic validity of two instruments for assessing anxiety and depression among pregnant women in Hyderabad, Pakistan. Health Care Women Int 2007, 28(6):556-572.

30. DeRubeis RJ, Hollon SD, Amsterdam JD, Shelton RC, Young PR, Saloman RM, O'Reardon JP, Lovett ML, Gladis MM, Brown LL, Gallop R: Cognitive therapy vs medications in the treatment of moderate to severe depression. Arch Gen Psychiatry 2005, 62(4):409-416.

31. Dennis C-L, Hodnett E: Psychosocial and psychological interventions for treating postpartum depression. Cochrane Database Syst Rev 2007, 4:CD006116.

32. Grote NK, Swartz HA, Geibal SL, Zuckoff A, Houck PR, Frank E: A randomized controlled trial of culturally relevant, brief interpersonal psychotherapy for perinatal depression. Psychiatr Serv 2009, 60(3):313-321

33. Frank E, Kupfer DJ, Buysse DJ, Swartz HA, Pilkonis PA, Houck PR, Rucci P, Novick DM, Grochocinski VJ, Stapf DM: Randomized trial of weekly, twice-monthly, and monthly interpersonal psychotherapy as maintenance treatment for women with recurrent depression. Am J Psychiatry 2007, 164:761-767.

34. Jarrett RB, Kraft D, Doyle J, Foster BM, Eaves GG, Silver PC: Preventing recurrent depression using cognitive therapy with and without a continuation phase: a randomized clinical trial. Arch Gen Psychiatry 2001, 58:381-388

35. Fava GA, Ruini C, Rafanelli C, Finos L, Conti S, Grandi S: Six-year outcome of Cognitive Behavioral Therapy for Prevention of Recurrent depression. Am J Psychiatry 2004, 161:1872-1876.

36. Hollon SD, Stewart MO, Strunk D: Enduring effects for cognitive behavior therapy in the treatment of depression and anxiety. Annu Rev Psychol 2006, 57:285-315.

37. Dobson KS, Hollon SD, Dimidjian S, Schmaling KB, Kohlenberg RJ, Gallop RJ, Rizvi SL, Gollan JK, Dunner DL, Jacobson NS: Randomized trial of behavioral activation, cognitive therapy and antidepressant medication in the prevention of relapse and recurrence in major depression. J Consult Clin Psychol 2008, 76(3):468-477.

38. Gul A, Ali BS: The onset and benefit from counseling by minimally trained counselors on anxiety and depression in women. $J$ Pak Med Assoc 2004, 54(11):549-552.
Pre-publication history

The pre-publication history for this paper can be accessed here: http://www.biomedcentral.com/1471-244X/10/57/prepub

doi: $10.1186 / 1471-244 X-10-57$

Cite this article as: Ali et al., Effectiveness of counseling for anxiety and depression in mothers of children ages 0-30 months by community workers in Karachi, Pakistan: a quasi experimental study BMC Psychiatry 2010, 10:57

\section{Submit your next manuscript to BioMed Central and take full advantage of:}

- Convenient online submission

- Thorough peer review

- No space constraints or color figure charges

- Immediate publication on acceptance

- Inclusion in PubMed, CAS, Scopus and Google Scholar

- Research which is freely available for redistribution
C BioMed Central 